\title{
DENTAL FEAR AND UTILISATION BEHAVIOUR AMONG ANTENATAL MOTHERS IN SEREMBAN DISTRICT
}

N.V. Savithri, R. Esa. Dental fear and utilisation behaviour among antenatal mothers in Seremban district. Annal Dent Univ Malaya 2008; 15(1): 2732 .

\section{ABSTRACT}

Dental fear is a hindrance to the effective provision of oral health care and causes patients to delay, or even avoid necessary care altogether. The aim of this study was to determine the prevalence and level of dental fear, to identify specific fear provoking stimuli and also to explore the avoidance behaviour among the respondents. A cross-sectional study was conducted on a sample of 407 antenatal mothers utilizing the Kleinknecht's Dental Fear Survey Questionnaire. The overall prevalence of dental fear was $94.1 \%$ of which $67.6 \%$ of the subjects reported low fear levels, $26.5 \%$ were moderately fearful while none were highly fearful. Only $5.9 \%$ of the subjects reported no fear. The drill and anaesthetic needle were identified as the most fear provoking objects. Subjects with moderate fear were about 6.4 times $(\mathrm{OR}=6.39 ; 95 \% \mathrm{CI} 3.81-10.75)$ more likely to avoid making appointments and 6 times $(\mathrm{OR}=6.05 ; 95 \%$ CI 3.20-11.50) more likely to cancel appointments compared to subjects with lower levels of fear. This study indicates that dental fear is a common problem among antenatal mothers contributing to poor dental attendance.

Key words: antenatal mothers, avoidance, dental anxiety, dental fear, utilization

\section{INTRODUCTION}

In spite of tremendous advances in dentistry with improved anesthetics and instrumentation, fear of dental services is still prevalent and freely admitted to by many people. Generally, few people are immune from some form of fear or anxiety problem. Early investigators found that dental fear is not homogenous in our populations but vary along a continuum, ranging from mild apprehension, which can be overcome by reassurance to abject phobia which prevents any dental procedures from being successfully completed (1).

The obvious consequence of a phobic reaction is the avoidance of dental treatment. Dental fear has been implicated as an important factor in broken or cancelled appointments (2). It has been repeatedly identified as a cause of delay in providing timely preventive and treatment services (3-4) resulting in
Original Article

N.V. Savithri ${ }^{1,2}, \mathrm{R}$. Esa $^{3}$
${ }^{1}$ Department of Community Dentistry
Faculty of Dentistry, University of Malaya
50603 Kuala Lumpur, Malaysia

2 Dental Department Seremban,
Negeri Sembilan, Malaysia
Email: Savithrinv@yahoo.com
3 Associate Professor
Department of Community Dentistry,
Faculty of Dentistry, University of Malaya,
50603 Kuala Lumpur, Malaysia
Tel. No: 0379674893
Fax. No: 03 79674532
Email: rashidah@,um.edu.my
Corresponding author: Dr. Rashidah Esa

catastrophic consequences (5). This avoidance and neglect often causes them to have more extensive tooth decay and periodontal problems.

Although it seems like the whole concept of dentistry is feared, most people are able to identify specific aspects of dentistry that frighten them most. The major stimuli that most often aroused anxiety were seeing the needle, feeling the drill, and feeling the pain in spite of the local anaesthesia (4-8).

In Malaysia, limited studies have been conducted in this field thus far. Investigations on antenatal mothers (9-10) have indicated that dental fear and anxiety was one of the causes of non-compliance to dental appointments. Other local studies have cited the drill and the needle as the most feared items (1112).

This study aims at providing an insight into the problem of stressful dental experiences, specifically among antenatal mothers who are one of the target groups for oral healthcare delivery in Malaysia. A mother's anxiety may be transferred to her child via modeling or even through more subtle forms of communication (13). The findings of this study can assist in understanding the extent of this problem and subsequently appropriate measures can be undertaken to overcome this obstacle in future.

\section{METHODS}

\section{Participants}

This study was conducted in the populous district of Seremban, Negeri Sembilan located along the west coast of Peninsula Malaysia. There are 8 
Government run Health clinics in this district. A non-probability sampling technique was used whereby four clinics with the highest attendances were selected due to manpower and resource constraints. Subsequently, all antenatal mothers attending the selected health clinics during the period allocated for data collection were selected. This cross-sectional study consisted of an interview questionnaire survey for which ethical clearance was obtained prior to data collection.

\section{Questionnaire survey}

Several questionnaires have been employed by many researchers to assess dental fear. The most widely used are the Dental Anxiety Scale (DAS) and the Dental Fear Survey (DFS). Both have been shown to be valid and reliable (14). The DAS is a shorter questionnaire which is useful as a predictor of patients' distress in the operatory. In contrast, the DFS questionnaire contains 20 items, each item graded on a 5-point Likert scale. A score of one or two indicates low fear while a score of four or five shows high fear. It covers three dimensions; avoidance of dental treatment, somatic symptoms of anxiety and anxiety caused by dental stimuli such as the smell of the operatory and the sight of the instruments (15).

In this study a modified Kleinknecht's DFS questionnaire was preferred because not only does its dimensions covers a wider perspective, its usage in many different populations allows ease of comparison. Furthermore, this questionnaire is suitable for this study as it has been cross-culturally validated in South East Asia (16). Permission to use the DFS questionnaire was obtained from the primary investigator, Ronald Kleinknecht. The questionnaire was translated into "Bahasa Melayu", the national language. It was then re-translated into English (back translation) to detect any anomalies incurred in the first translation. The questionnaire was then face validated by two Dental Public Health officers and pre-tested on 30 respondents not from the final sample. Any ambiguities in the questionnaires were modified accordingly. In addition sociodemographic data of the respondents were also included in the questionnaire. During the survey, the DFS showed good reliability for all the 3 dimensions (Cronbach's alpha values for avoidance of dental treatment $(0.71)$, somatic symptoms of anxiety $(0.71)$ and anxiety caused by dental stimuli $(0.91)$.

Two Dental Surgery Assistants were trained as interviewers and recorders by the investigator prior to data collection. The DFS questionnaire is usually self-administered but in this survey the participants were interviewed instead. This is because the antenatal mothers came from different educational levels and some may not be able to comprehend the questionnaire. The face-to-face interview was conducted in privacy to minimize biased responses.

\section{Statistical methods}

All data collected was analysed using SPSS version 12. Simple descriptive statistics were used to describe the central tendency and variation in the data. Chi-square test was used to analyse the difference in avoidance behaviour between subjects with different levels of fear. Independent t-tests were used to compare differences in responses between groups with different fear levels.

\section{RESULTS}

\section{Sociodemographic profile}

The sample population consisted of 407 antenatal mothers from the three main ethnic groups namely Malays, Chinese and Indians which is reflective of the study population in Seremban (Table 1). Their ages ranged from 17 to 43 , the mean age being 27.8 years (s.d.5.0)

\section{Levels of fear}

Figure 1 shows the distribution of Dental Fear Survey (DFS) scores for the prevalence of fear. A total score of 20 for the twenty items indicates "no fear", a score of 21-40 means "low fear", a score of 41-79 shows "moderate fear" while a score of 80 and above would indicate "high fear". The mean DFS score for all subjects was 35.1 (s.d.11.4). The overall prevalence of dental fear was $94.1 \%$.

\section{Avoidance of dental treatment}

Table 2 shows the avoidance behaviour of the subjects. This was assessed based on their ratings on two items, i.e. 1) putting off making appointment and 2) canceling or not turning up for appointment out of fear of dental work. The rating was done

Table 1. Sociodemographic profile of the sample

\begin{tabular}{llcr}
\hline Subject & characteristics & $\begin{array}{c}\text { No. of } \\
\text { subjects } \\
(\mathrm{n}=407)\end{array}$ & $\%$ \\
\hline \multirow{2}{*}{ Age } & $\leq 24$ & 104 & 25.6 \\
& $25-29$ & 163 & 40.0 \\
& $30-34$ & 102 & 25.1 \\
& $\geq 35$ & 38 & 9.3 \\
Ethnicity & Malay & 238 & 58.5 \\
& Chinese & 70 & 17.2 \\
& Indian & 99 & 24.3 \\
Level of & Tertiary (University/College) & 88 & 21.6 \\
education & Upper secondary & 226 & 55.5 \\
& (STPM/SPM/Nocational) & & \\
& Lower secondary \& Primary & 93 & 22.9 \\
& (PMR/Primary) & & \\
Income & above RM3500 & & \\
& RM1500-RM3500 & 83 & 20.4 \\
& below RM1500 & 223 & 54.8 \\
& & 101 & 24.8 \\
\hline
\end{tabular}




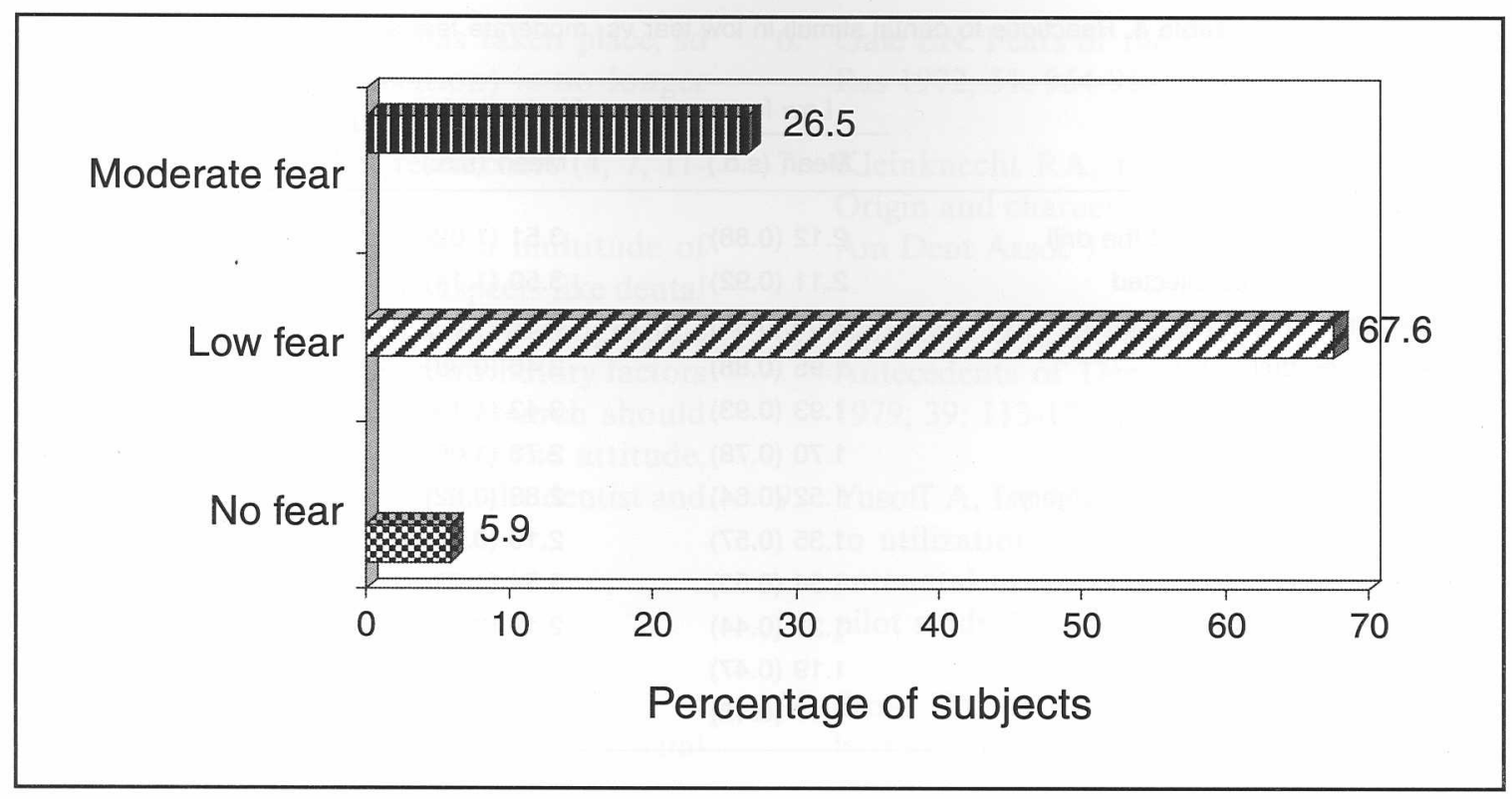

Figure 1: Distribution of levels of fear.

Table 2. Avoidance behaviour of subjects

\begin{tabular}{|c|c|c|c|c|c|c|}
\hline \multirow{2}{*}{ Level of fear } & \multicolumn{3}{|c|}{ Put off making appointment } & \multicolumn{3}{|c|}{ Cancel appointment } \\
\hline & Yes & No & Total & Yes & No & Total \\
\hline Moderate fear & $64(59.3 \%)$ & $44(40.7 \%)$ & $108(100 \%)$ & $36(33.3 \%)$ & $72(66.7 \%)$ & $108(100 \%)$ \\
\hline Low fear & $51(18.5 \%)$ & $224(81.5 \%)$ & $275(100 \%)$ & $21(7.6 \%)$ & $254(92.4 \%)$ & $275(100 \%)$ \\
\hline \multirow[t]{2}{*}{ Total } & $115(30 \%)$ & $268(70 \%)$ & $383(100 \%)$ & $57(14.9 \%)$ & $326(85.1 \%)$ & $383(100 \%)$ \\
\hline & \multicolumn{3}{|c|}{$\begin{array}{c}\text { OR }=6.39(95 \% \text { Cl } 3.81-10.75) \\
p \text {-value }=0.000\end{array}$} & \multicolumn{3}{|c|}{$\begin{array}{c}\text { OR }=6.05(95 \% \mathrm{Cl} 3.20-11.50) \\
p \text {-value }=0.000\end{array}$} \\
\hline
\end{tabular}

Chi-square test $p<0.05$

using a scale of $1-5$ where ' $1=$ never, $2=$ once or twice, $3=$ a few times, $4=$ often and $5=$ always. A significantly stronger avoidance behaviour $(p=0.000)$ was present among the moderately fearful subjects.

\section{Fear and anxiety caused by various dental stimuli}

Twelve dental situations were listed in the questionnaire. Subjects were required to rate their feelings of fear, anxiety or unpleasantness towards these situations on a scale of 1-5 $(1=$ not at all, $5=$ very much). The ranking of these dental situations are shown in Table 3. Overall situations related to dental procedures seem to arouse more fear compared to non-dental procedures. Topping the list was feeling the 'vibrations of the drill' and 'feeling the needle being injected'.

\section{Comparison of rankings between subjects with} different levels of fear

Though the ratings for the low fear and moderate fear groups differed significantly
Table 3. Ranking of dental stimuli of all subjects

\begin{tabular}{ll}
\hline Ranking of Dental Stimuli & Mean (s.d.) \\
\hline 1. Feeling the vibrations of the drill & $2.43(1.14)$ \\
2. Feeling the needle injected & $2.42(1.18)$ \\
3. Seeing the anaesthetic needle & $2.34(1.16)$ \\
4. Hearing the drill & $2.29(1.14)$ \\
5. Seeing the drill & $2.27(1.20)$ \\
6. Having your teeth cleaned & $1.93(0.98)$ \\
7. Being seated in the dental surgery & $1.84(0.94)$ \\
8. Seeing the dentist walk in & $1.64(0.88)$ \\
9. Smell of the surgery & $1.53(0.76)$ \\
10. Sitting in the waiting room & $1.45(0.76)$ \\
11. Approaching the dental clinic & $1.40(0.73)$ \\
12. Making appointment & $1.38(0.71)$
\end{tabular}

$(p=0.000)$, the rankings of the items were quite similar among the two groups (Table 4). The anaesthetic needle and the drill were ranked as most 
Table 4. Reactions to dental stimuli in low fear vs moderate fear subjects

\begin{tabular}{lccc}
\hline \multirow{2}{*}{ Dental stimuli } & Low fear & Moderate fear & t test (95\% C.I.) \\
\cline { 2 - 3 } & Mean (s.d.) & Mean (s.d.) & 0.000 \\
\hline Feeling the vibrations of the drill & $2.12(0.88)$ & $3.51(1.02)$ & 0.000 \\
Feeling the needle injected & $2.11(0.92)$ & $3.50(1.14)$ & 0.000 \\
Seeing the anaesthetic needle & $2.00(0.89)$ & $3.52(1.00)$ & 0.000 \\
Hearing the drill & $1.95(0.88)$ & $3.46(0.98)$ & 0.000 \\
Seeing the drill & $1.93(0.93)$ & $3.43(1.10)$ & 0.000 \\
Having your teeth cleaned & $1.70(0.78)$ & $2.73(1.05)$ & 0.000 \\
Being seated in the dental surgery & $1.52(0.64)$ & $2.83(0.92)$ & 0.000 \\
Smell of the surgery & $1.35(0.57)$ & $2.10(0.94)$ & 0.000 \\
Seeing the dentist walk in & $1.34(0.55)$ & $2.54(1.03)$ & 0.000 \\
Sitting in the waiting room & $1.21(0.44)$ & $2.19(0.97)$ & 0.000 \\
Making appointment & $1.19(0.47)$ & $1.95(0.94)$ & 0.000 \\
Approaching the dental clinic & $1.17(0.43)$ & $2.06(0.96)$ & \\
\hline
\end{tabular}

Independent $t$ test $\mathrm{p}<0.05$

fearful by both groups. However for the low fear group, 'feeling the needle being injected' was most provoking compared to the moderate fear subjects who perceived 'seeing the anaesthetic needle' as most fear provoking. For both groups, feeling the vibration of the drill evoked more fear compared to seeing the drill or hearing the drill. Among the nonoperative procedures, almost similar ranking were observed in both groups.

\section{DISCUSSION}

\section{Avoidance behaviour of subjects}

There appears to be a significant association between level of fear and habit of putting off making an appointment among these subjects. Local studies on antenatal mothers have indicated that one of the reasons for non-compliance to dental appointments was dental fear and anxiety (9-10). Fear has also been cited as a cause of delay in utilization of dental services by Malaysians (17).

The avoidance behaviour of these subjects is also comparable to some overseas studies. Researchers in Western as well as Asian countries have shown that higher levels of fear are associated with avoidance in seeking treatment (18-19). It appears that delaying dental treatment is a common problem worldwide and can become a significant barrier to dental care if ignored. This avoidance and subsequent neglect often causes them to have more extensive tooth decay and periodontal problems. This poses a problem to the dentist as they require extensive treatment and longer chairside time. Nevertheless, we must not dismiss the fact that there are other contributory factors to the dental avoidance behaviour. Skaret et al (20) had highlighted that negative beliefs of dentist and dislike of the dentist also has an influence on missed or cancelled appointments.

\section{Fear and anxiety to dental stimuli}

In this study, the moderately fearful subjects exhibited a significantly greater intensity of fear for all the dental situations with the drill and the needle as the most fear provoking stimuli. Similar findings were cited in numerous other studies $(1,4,7,21-25)$.

A possible explanation for this is that the drill and anesthetic needle are associated with anticipation of pain. It has been demonstrated that most patients attribute at least part of their feeling of fear and anxiety to the expectation of pain during dental procedures (7). Lautch (26) also found that fearful patients had lower pain thresholds which increase their anxiety towards dental procedures. The contribution of pain expectations to dental anxiety, and also to dental avoidance, suggests that this might usefully be a specific focus of intervention in programmes to reduce dental anxiety. It may well be that the fear producing effect of pain can be mitigated by the professional behaviour and personal characteristics of the dentist.

Interesting differences were observed between subjects having different levels of fear. In the 'low fear' group, their most feared situation was 'feeling the vibration of the drill'. 'Seeing the drill' did not trigger much fear. In contrast, moderately fearful subjects gave the highest rating to the 'sight of the syringe'. This indicates that the 'low fear' subjects are aggravated by the actual treatment procedure itself whereas the 'moderate fear' subjects seem to display higher intensity of fear even before treatment begins! This goes to show that possibly the moderate fear group are easily aroused and just the thought of the injection itself exacerbates fear levels. The fact that the sight of the needle is rated highly 
suggests that fear conditioning has taken place, so the real stimulus (needle sensation) is no longer needed to produce fear reactions. This finding is consistent with that of earlier researchers $(4,7,11$ 12, 22).

Fear and anxiety is caused by a multitude of factors. Though this study covers aspects like dental situations, clinical procedures, sociodemographic characteristics of subjects, other contributory factors must also be considered. Future research should investigate other predictors such as the attitude, communication skills, competency of the dentist and patient management skills.

\section{CONCLUSION}

Dental fear is a common problem among ante natal mothers contributing to poor utilization behaviour. Hence, appropriate management of dental fear needs to be instituted to enhance utilization of oral health care services in this target group.

\section{ACKNOWLEDGEMENTS}

This study was supported by a grant from the University of Malaya, No.F/106C. The authors thank the study respondents and all the staff in the participating health clinics for their support and cooperation.

\section{REFERENCES}

1. Scott DS, Hirschman R. Psychological aspects of dental anxiety in adults. J Am Dent Assoc 1982; 104: 27-31.

2. Kleinknecht RA, Bernstein DA. The assessment of Dental Fear. Behaviour Therapy 1978; 9: 626634.

3. Gatchel RJ, Ingersoll BD, Bowman L. The prevalence of dental fear and avoidance: a recent survey study. J Am Dent Assoc 1983; 107: 609610.

4. Milgrom P, Fiset L, Melnick S, Weinstein P. The Prevalence and Practice Management. Consequences of Dental Fear in a Major US City. J Am Dent Assoc 1988; 116: 641-646.

5. Kaufman E, Sher Rand R, Gordon M, Cohen H. Dental Anxiety and Oral Health in Young Israeli Male Adults. Commuunity Dent. Oral Epidemiol 1992; 9: 125-132.
6. Gale EN. Fears of the Dental Situation. J Dent Res 1972; 51: 964-966.

7. Kleinknecht RA, Klepac RK, Alexander LD. Origin and characteristics of fear of dentistry. J Am Dent Assoc 1973; 86: 842-848.

8. Bernstein DA, Kleinknecht RA, Alexander LD. Antecedents of Dental Fear. J Pub Hlth Dent 1979; 39: 113-124.

9. Yusoff A, Isa MI, Jaafar N, Razak IA. Barriers to utilization of dental services among Malay antenatal mothers in Pasir Mas, Kelantan: A pilot study 1999. (Personal communication)

10. Siow YY. Oral health status and perceived barriers to utilization of oral health care among ante natal mothers. Faculty of Dent. Univ. Malaya, MCD thesis 2001.

11. Mohamed N. Dental Anxiety and Fear Among Trainee School Teachers in Malacca. Faculty of Dent. Univ. Malaya MCD thesis 2001.

12. Ong AL. Dental Fear and Caries status among 16-year-old schoolchildren. Faculty of Dent. Univ. Malaya MCD thesis 2002.

13. Klingberg G, Berggren U, Carlsson, Noren JG. Dental Fear in an urban Swedish child population: prevalence and concomitant factors. Community Dent Health 1994; 11: 208-214.

14. Schuurs AHB, Hoogstraten J. Appraisal of dental anxiety and fears questionnaire: A review. Community Dent Oral Epidemiol 1993; 21: 329339.

15. Kleinknecht RA, Thorndike RM. Factor analysis of the dental fear survey with cross validation. J Am Dent Assoc 1984; 108: 1984.

16. Milgrom P, Kleinknecht, RA, Elliott J, Liu HS, Teo CS. A Cross-cultural Cross Validation of the Dental Fear Survey in South East Asia, Behav Res Ther 1990; 28(3): 227-233.

17. Jaafar N, Jallaluddin RL, Razak IA, Esa R. Investigation of Delay in utilization of Government Dental Services in Malaysia. Community Dent Oral Epidemiol 1992; 20: 144147.

18. Locker D, Liddel A, Dempster L, Shapiro D. Age of onset of dental anxiety. J Dent Res 1999; 78: 790-796. 
19. Hagglin C, Hakeberg M, Ahlquist M, Sullivan M, Berggren U. Factors associated with dental anxiety and attendance in middle-aged and elderly women. Community Dent Oral Epidemiol 2000; 28: 451-60.

20. Skaret E, Raadal M, Kvale G, Berg E. Factors related to missed and cancelled dental appointments among adolescents in Norway. Eur J Oral Sci 2000; 108: 175-183.

21. Berggren U, Meynert G. Dental Fear and Avoidance: Causes, Symptoms, and Consequences J Am Dent Assoc 1984; 109: 247- 251.

22. Domoto PK, Weinsrein P, Melnick S. Results of a dental fear survey in Japan: implications for dental public health in Asia. Community Dent Oral Epidemiol 1988; 16:199-201.
23. Teo CS, Foong W, Lui HH, Vignesha H, Elliot J. Prevalence of dental fear in young adult Singaporeans. Int Dent J 1990; 40(1): 37-40.

24 Moore R, Birn H, Kirkegaard E, Brodsgaard I, Scheutz F. Prevalence and characteristics of Dental anxiety in Danish adults. Community Dent. Oral Epidemiol 1993; 21(5): 292-296.

25. Peretz B, Mann J. Dental anxiety among Israeli dental students: a 4- year longitudinal study. Eur J Dent Educ 2000; 4: 133-137.

26. Lautch H. Dental phobia. Br J Psych 1971; 119: 151-158. 